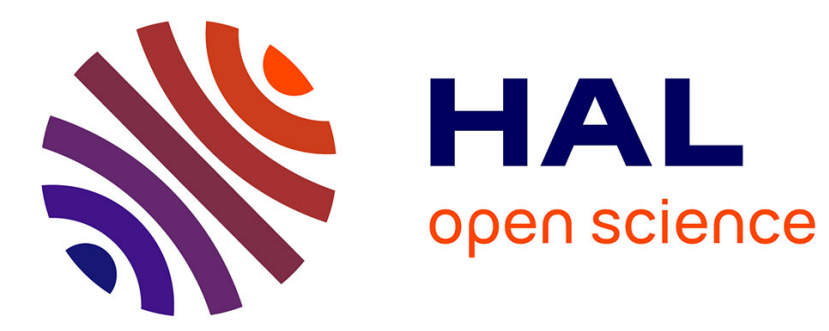

\title{
Synergetic Economics. Scientifical Approaches of Synergistic Economic Networks and Systems
}

\author{
Laura Melinda Stan
}

\section{To cite this version:}

Laura Melinda Stan. Synergetic Economics. Scientifical Approaches of Synergistic Economic Networks and Systems. CS-DC'15 World e-conference, Sep 2015, Tempe, United States. hal-01291111

\section{HAL Id: hal-01291111 \\ https://hal.science/hal-01291111}

Submitted on 20 Mar 2016

HAL is a multi-disciplinary open access archive for the deposit and dissemination of scientific research documents, whether they are published or not. The documents may come from teaching and research institutions in France or abroad, or from public or private research centers.
L'archive ouverte pluridisciplinaire HAL, est destinée au dépôt et à la diffusion de documents scientifiques de niveau recherche, publiés ou non, émanant des établissements d'enseignement et de recherche français ou étrangers, des laboratoires publics ou privés. 


\title{
Synergetic Economics. Scientifical Approaches of Synergistic Economic Networks and Systems
}

\author{
Laura Melinda Stan \\ PhD graduate of the Faculty of Economics and Business Administration, \\ West University of Timişoara, Romania \\ stan.melinda@gmail.com
}

\begin{abstract}
Synergetic Economics represents an upper stage of approaching comprehensive collaborative economic networks and systems. Taking into account the high number of unsystematic approaches of the synergy phenomenon - which is characteristic for the complex systems -, the present work represents a rundown of pragmatic and scientific approaches of the entities which try out, build and exploit synergy effects in economics and other areas. In this regard, the present paper sustains the scientific research in highlighting synergy as an empirical phenomenon which can be treated (in the sense of identifying, researching and comparing) from the quality and quantity point of view at the level of complex networks and systems.
\end{abstract}

Keywords: Synergy - Synergetics - Synergistic Economic Networks Open Economic Systems

\section{Introduction}

The present competition between the active entities of the socio-economic environment (in the context of shortages of resources, competencies and required knowledge) is governed by the imperative of the deep collaborative efforts' increasing efficiency. For the past ten years, the use of the micro- and macrosynergism's specific prefixes (co-: cooperation, coordination, coworking, co-opting and con-: conglomeration, conglobing etc.) has been expanding in literature. On these lines, the intrinsic issue with literature, became the understanding of the meaning of synergy [1] and the understanding of the way in which this phenomenon can amplify the competitive success of networks and systems represented at different levels.

Synergetics is still treated as a new science, unconventionally applied in Economics; furthermore, the statistics continue to be extremely vague in this phenomenon's highlighting. Synergetics (and implicitly Synergetics studies applied in Economics) is focused on the study of collaborative behavior of entities of different natures and on 
the study of the way in which these ones manage their complexity in order to increase their value. On these lines, synergy is assigned to proactive and super efficiencyoriented entities with strategic collaborative excellence; synergy is a property of all entities who turn to combined increased efforts, with multiplicative effects, through reinvented and repositioned ${ }^{1}$ tools.

Forasmuch as synergy emerges through extremely varied dynamic frames and contexts, Synergetic Economics accordingly is an interdisciplinary science, in flux, as the economic and social entities become more open, more dynamic and interconnected with the elements of the environment in which they operate ${ }^{2}$. This branch of Synergetics has in the foreground the possibility of creating added value through comprehensive collaborative relationships - in the collaborative social systems' case, as well as in the economic or other types of systems' case -.

\section{The Evolution of Synergetics Studies in the Economic Field}

From the etymological point of view the "synergy" concept was used for the first time around the 17th century, originating from the Greek ,synergos“ term which defines the action of working together or of cooperate. "If during this period the synergy concept was mainly used in the theological field (describing "the cooperation of human effort with divine will"), in the XIX and XX century, "synergy" was promoted in physics and biochemistry" [2].

In economy, "synergy" was approached for the first time in the '60s-'70s, within the studies of open economic systems, in the context in which the transition towards open-natural systems was noted. But the concept has been sluggishly integrated in management and economy; as a result, the verb ,to synergize، ${ }^{63}$ was introduced in English only in 2009-2010 (in U.S.A.) [3] - concurrently with the amplification of the synergy phenomenon in the global economic crisis' context ${ }^{4}$. Researching the systematic ,soundings" of the synergy concepts, I identified at least six evolutionary phases for the study of active economic entities' synergy (see figure1):

1 În the maximum efficiency positions, with maximum utility for network or system.

2 See the transition from closed-rational systems, with rigorous collaborative behaviors (19001930) to closed-natural (social) systems - theory Y of integration - (1930-1960), to openrational systems, based on the interfering of internal systems' components/mechanisms with those of the environment - according to the contingency theory - (1960-1970), and to opennatural (social) systems - according to the organization theory, the institutional theory, the social ecological theory and the resource dependence theory -, the specific actions of these entities (mergers, joint ventures, alliances, co-options, diversifications, political involvements etc.), being specific elements of synergistic structures (1970-present).

3 Which means acting with/through synergy, manifesting synergy, cooperating with others to remedy something, determining synergistic actions.

4 When the added value's creation through comprehensive collaborative efforts has become an imperative for the active economic and social entities and the emergence of negative synergies required a better knowledge of the value creation chain's mechanisms. 
I. The precursory phase of Synergetics development as an interdisciplinary science applicable (also) in Economics (1963-1970) - R. Buckminster Fuller (futurist and systems theorist) approaches in an innovative way the open systems, from the perspective of the fact that these entities - as a whole - constitute results of synergy effects insured by the constituent subsystems' deep pulling together [4]. Therefore, he will get to lay the foundations of a future new science, the Synergetics (unfraimed in the respective period), paying attention to its multiple implications in the field of exact and social sciences; as a result, Igor Ansoff, the father of strategic management, introduces synergy for the first time in the study of the open economic systems (1965), but approaching the concept (even in the next two decades) only from the management perspective - at business level and rarely at industries level [5, 6, 7].

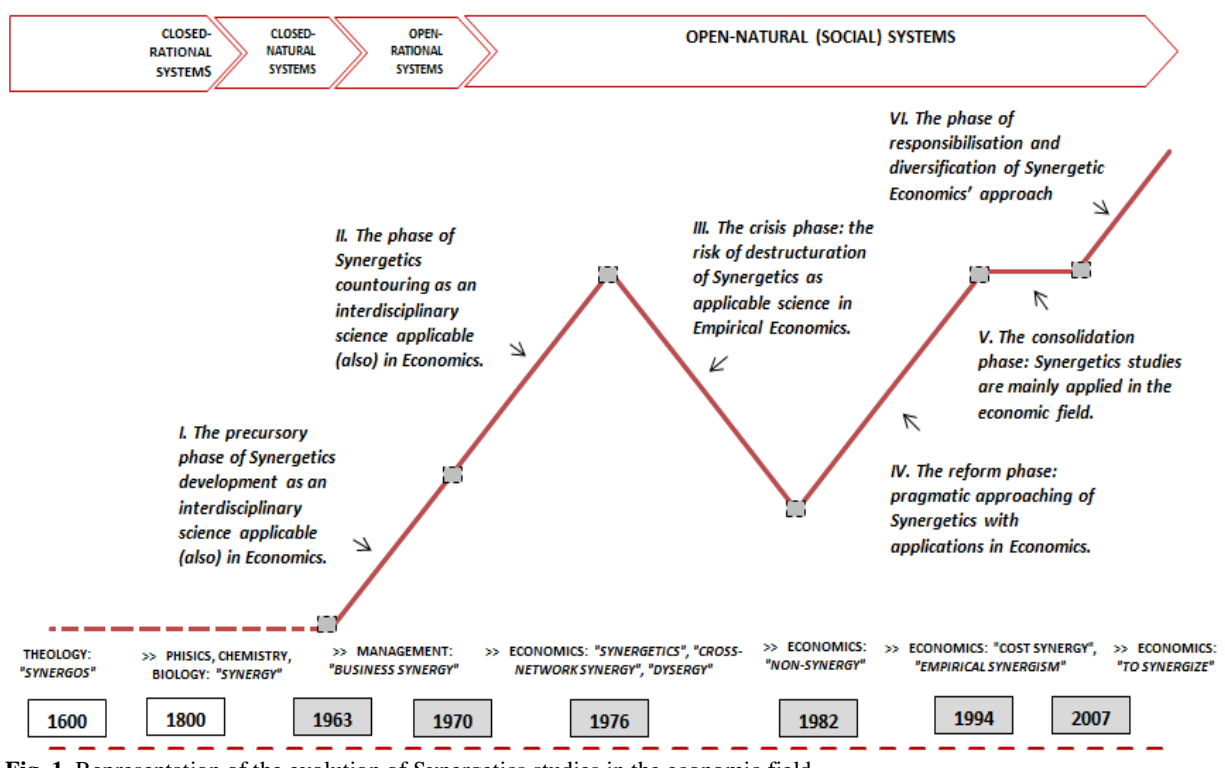

Fig. 1. Representation of the evolution of Synergetics studies in the economic field

II. The phase of Synergetics countouring as an interdisciplinary science applicable (also) in Economics (19711976). As a result of the introduction in the U.S.A. of the synergy concept in the study of Economics, Synergetics began to be treated as an interdisciplinary science, correlated with the economic life from the ephemeralization perspective, <<doing more and more with less and less resources $>>$, especially through the technological advance's ability [8] (therefore creating exponentially abounding and diversified goods and services). Thus, new correlated concepts come to light, such as technological convergence or information flows between the component subsystems of an economic entity [9]. Due to the diversification of approaching, in Great Britain, A. Coulter comes to conclude that "synergy is of universal applicability. It can be applied not only to human mind, but also to human groups, to organizations of all kind, to industrial entreprises, to entire economic systems" [10].

III. The crisis phase: the risk of destructuration of Synergetics as applicable science in Empirical Economics (1977-1982). As the oil crisis' domino effect has affected the 
entire Western economic system at the end of the '70s, more and more caterwauls appeared against Synergetics as applicable science in Economics. At micro- and macro- level repeated failures in shaping synergy into practice were noticed, seeming that sophistries took the place of synergism applicability. One of the reasons was the fact that synergy became an abused concept in the economic speech, and, consequently, misinterpreted. It was believed that through the simple combination of capacities and efforts, synergy is obtained anytime/anyway, without taking into account the redundancies/false synergies/dysergies/non-existent collaborative strategies. "By the late 1970s, however, enthusiasm for synergy had waned. It seemed that synergy was a nice idea, but it rarely occurred in practice (...). Firms often used it only to justify the actions undertaken for other reasons" [11] (particularly with the aim of quickly attracting investments), which affected the adequate understanding and exploitation of synergistic potential.

$I V$. The reform phase: pragmatic approaching of Synergetics with applications in Economics (1983-1994). Despite the synergy's description in pretty vague terms in the economic and management literature, some entities steeply climbed in the global competitive hierarchy in the late 70 s and in the ' $80 \mathrm{~s}$, benefiting from unexpected generous results, synergy producing exponential effects beyond the handy elements [12]; practically, these entities' (such as Microsoft Corporation, Apple Inc., the Japan's electronics industry or the fax industry from Taiwan) activities were based on the principle of complementarity, innovation and continuous transfer of know-how among units with different functions; furthermore, the receptivity for the external environmental opportunities and the propagation of cross-functional support have determined the detaching of these synergistic entities from the classic economic competitors. As a result, Synergetics "reinvented" itself, becoming in a renewable way a systematic knowledge assembly regarding synergy based on empiricism (see the works of R. Buckminster Fuller, W. Weidlich, G. Haag, P.A. Corning, M. Porter etc. from the 80s-90s).

$V$. The consolidation phase: Synergetics studies are mainly applied in the economic field (1995 - 2006). As a result of the review of Synergetics approach, generating added value through the profound combination of efforts, know-how or collaborative networks began to be studied mainly in economic and management fields; synergy's definitions were renewed in the Western dictionaries, the first explanation criterion of synergy phenomenon being the economic and management criterion $[13,14]$. Between 1995-2006, the great part of the books published in the world on the Synergetics' theme, approached also its economic component, focusing on: $(a)$ synergy resulted in the context of mergers, acquisitions and alliances [15]; (b) organizational cultures explained through economic networks' synergizing [16] (that requires creative, strategic and transformational thinking [17]); (c) cost reductions generated through the identification and optimal exploitation of the active economic system's interdependent resources [18]; (d) exploitation of collaborative networks' synergistic potential determining the creation of a new level of economic performance [19]; (e) spatial synergistic (urban) networks' development, which determined the regional/national clusters' consolidation [21] etc. 
VI. The phase of responsibilisation and diversification of Synergetic Economics' approach (2007 - prezent). In the context in which a series of economic entities proved to be deeply affected by the global economic crisis, synergeticists began to be mainly concerned with (1) the diagnosis of economic systems which failed in the extended competitive environment, and (2) the way in which the synergistic networks are and should be generated and monitored in the crisis affected economic environment. These researches led to the rise of the era of synergistic potential's exploitation strategies [22], Synergetics being regarded as one of the primary solutions for the exit from the <created chaos>. The American researches drew attention to the fact that "synergy is not an unitary phenomenon" [23], there being a variety of applications of synergistic functions and possible synergy effects: positive and negative synergies, maximal and minimal synergies etc. In Europe, the initiated studies correlated Synergetics with cognitive economy [24]; furthermore, they have laid the foundation for the horizontal and vertical synergistic networks theory, the vertical networks (based on the functions and capacities' complementarity) being the most complex ones, such as the type of conglomerates or polycentric urban regions, like the Ranstad region from the Netherlands [25]. The passage from an economic system's units' descentralization towards reconnecting dispersed units and capacities through consolidating geographic synergistic networks can be noticed, the tendency being to promote the most concentrated collaborative processes.

Related to the systems' failures in controling the crisis' negative effects, J. A. Lybeck drew attention to the lack of the synergistic infrastructure's control. For example, the 50 State departments of the U.S. financial institutions had separate or superposed jurisdictions during the outbreak of the economic crisis in 2007, this situation leading to the insurance companies' Federal non-surveillance [26] and to the transfer of the low yields from a unit to another interconnected entity. As a result, the Financial Stability Board identified "thirty financial groups worldwide that are considered to create systemic risk and should be supervised cross-border" [26].

The diversification of Synergetic Economics' research approach also continues in the present, concludent results of this stage being systematized as they represent the passage to another future phase. By that time, we can take into account the recent works of Q. Bai, S. Banerjee, E. Frehland, H. Haken, A. Liening, A.S. Puryaev, L.M. Stan, V.V. Yakimtsov etc., focused on the Synergetic Economics' implication in the management of complex systems affected by the local, sectorial and global crisis.

\section{The Genesis and Evolution of Synergistic Network and System}

The tangible and intangible support of the economic synergistic actions is constituted by the synergistic network, the assembly of capacities and flows of different natures from which optimally exploited interdependence, the economic entity benefits from synergy effects. In contradiction to the economic system which is a complex construction of interdependent resources which constitute a whole, the synergistic network presents itself much more prominently with synergistic functions of links' facilitation. The literature emphasizes most of all the active economic networks' synergy, because these entities have as primary role the links' creation between two or more systems and subsystems; the scope is to proactively facilitate the optimum trans- 
fer of know-how, resources and other capacities needed by production or other type of systems. If the economic systems also depend on synergies, the economic networks depend most of all on synergies (having synergies' facilitation as primary role)!

The typical synergistic entities are the ones which reinvent the collaborative behavior when a disequilibrium is produced (in moment T): an apparent disorder/chaos in which the respective network/system is induced, resulting certain conflicts/opposing processes which require reorganization and profound collaboration between the present (new and preexistent) elements - see figure 2:

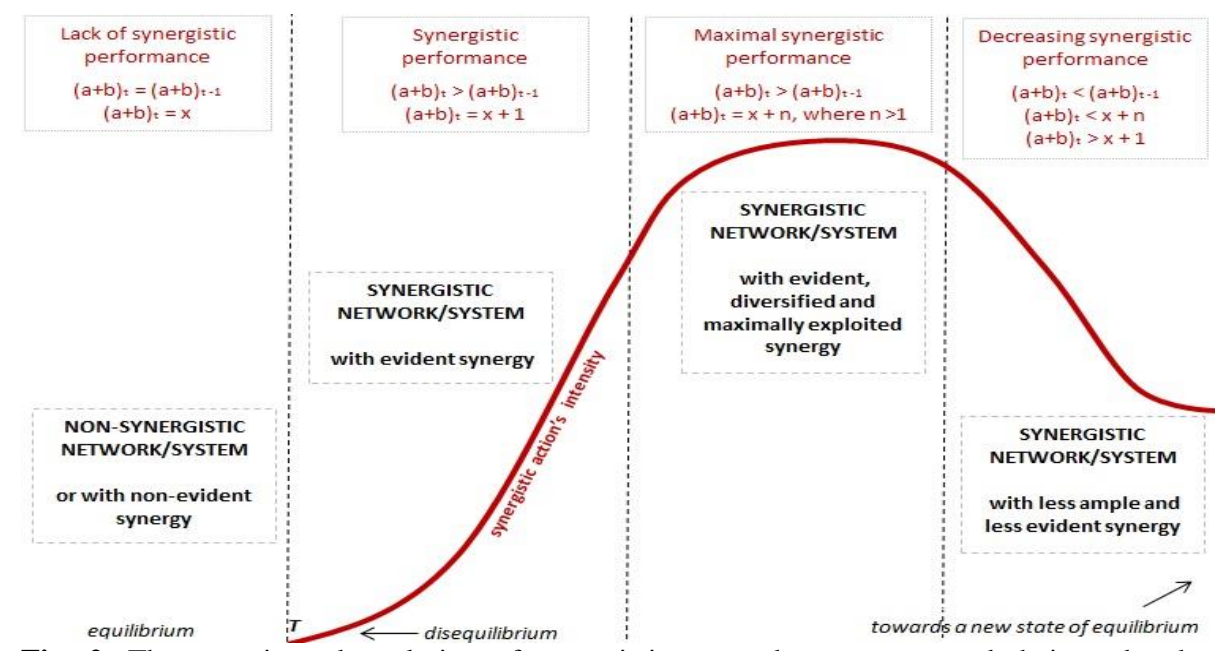

Fig. 2. The genesis and evolution of synergistic network or system and their undertaken synergistic actions' intensity. Examples of associated synergistic performances

As a result of processes and collaborative flows' reorganization and repositioning of technological, informational and financial resources, an increased <whole> as val$\mathrm{ue}^{5}$ is created (the collaboration between the $a$ and $b$ entities in the moment $t$ having a greater value than the earlier collaborative results), tending to a diversification of included value chains. Subsequently, through the search and finding of a new state of equilibrium/symmetry (when the resources crisis is reduced), the synergistic actions' intensity decreases and the collaborative processes (by $a+b$ type) tend to deploy at a minimal, standardized level. From the moment of facing with a situation of <apparent chaos> (moment $T$ ), synergy may occur in a moment after $(T+1$ or $T+n)$ because of the resistance to change/compromise/flexibilization of new required relationships or processes. If the produced disequilibrium is one scheduled (induced voluntarily) or prefigured in $T-1$ or $T-n$ moment, the resistance to change may take place "from time", the synergistic strategy itself being applied no later than the moment in which the disequilibrium, chaos or $N E W$ is confirmed in that entity's activities ${ }^{6}$.

\footnotetext{
${ }^{5}$ In terms of synergies with corresponding utility for the new needs of system/network.

${ }^{6}$ Examples of announced disequilibriums: scheduled mergers/alliances/relocations, the news of a direct competitor's appearance, the intention of connecting to the intermodal transport system, the change of legislation or of administrative regions, the liberalization of goods circulation etc.
} 


\subsection{The Synergistic Actions' Determinants in Economy}

Due to the doctoral research of the premises and synergistic actions' determinants in economy, I got to outline the synergistic gravity equation (SYNGEq) that represents "a synthesis of the endogenous and exogenous factors which determine the private and non-private economic decision makers to call to actions of synergistic exploitation of the economic network in which they operate" [2]. This equation can also be applied to non-economic (but social) entities which are competing. SYNGEq consists of the following elements (in which the 'imperatives' may mean 'necessities') [2]:

$$
\sum S Y N . \text { Act }=\sum R^{-} \bullet \mathbf{I}\left(\text { CRed }+\operatorname{Coop}^{+}+\mathbf{A}^{\text {Unimit. }}\right) \bullet \mathbf{V}(\text { Cust }+ \text { Info }) \bullet c c
$$

where:

$\sum \mathrm{SYN}$.Act $=$ the sum of the synergistic actions adopted by the economic actor

$\sum \mathrm{R}^{-}=$the amount of unpurchased but necessary resources of capacities

ICRed $=$ the imperative for cost reductions (the global costs)

$\mathrm{ICOOP}^{+}=$the imperative for deep cooperation (for the functional interdependence's increasing)

$\mathrm{IA}^{\text {Unimit. }}=$ the imperative for purchasing unimitable competitive advantages

VCust $=$ the necessity for customer value's increase

VInfo $=$ the necessity for informational value's increase

$c c=$ the specific environmental competitive conditions in which the economic actor operates

For example, SYNGEq helps to demonstrate the difference which exists between the prevailing synergistic actions' determinants in developed countries, with a national synergistic strategy of the cluster's system (the case of VInfo's prevelance in France) and the synergistic actions' determinants which prevail in less developed countries, without any national synergistic strategy (the case of $I A^{\text {Unimit. }}$ s prevelance to the right of less interconnected economic entities such as those from Romania). Concrete examples of SYNGEq's applicability will be presented in upcoming articles beside the post-crisis specific synergistic actions' determinants.

\subsection{The Evolution of Active Economic System's Synergistic Potential and its Degree of Exploitation}

The undertaking of synergistic actions is generated, as we saw, by different endogenous and exogenous determinants, but the synergistic potential's degree of exploitation (SYNP) of an open economic system also changes depending on a series of social components. A very important factor to be taken into account is the type of system's organizational structure. SYNP is not exploited directly proportional to its evolution (in percentage) because the variables of synergistic exploitation's capacity ${ }^{7}$ become the more numerous as the complexity of system/network increases, and this fact also requires specific synergistic strategies which limit to a certain extent the exploiting of the whole valid synergistic potential (see figure 3).

The entities which have a higher capacity of SYNP exploitation are those which

7 The flow of resources, the internal bureaucracy, the number of interested groups/social partners involved, etc. 
resort to global synergistic strategies, these ones being especially the young and less complex entities (small companies, newly-established business incubators, clusters of zonal vocation etc.); they have a higher synergizing ability of the internal and external capacities forasmuch "they gain perspectives across the entire business instead of a small functional area" [27], being able to prevent the possible synergistic counterperformances and to optimally place of know-how, human resources, technologies etc. in pole position. For all that, the most prepared entities for complex synergistic strategies are the mature ones (for example: transnational corporations, clusters of national or international vocations), these structures benefiting from: a significant integration and use of ICT, a more advanced available know-how and numerous and manifold human/material resources - all these generating mostly vertical synergies based on complementarity relations.

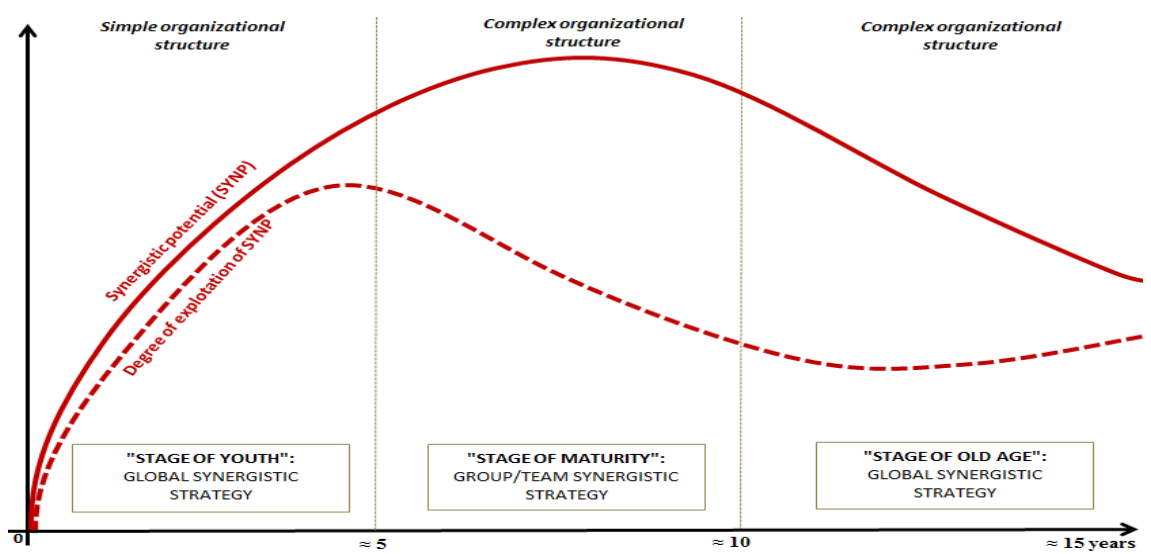

Fig. 3. The evolution of active economic system's synergistic potential and its degree of exploitation in terms of the evolution stage of the economic entity's general development. Specific synergistic strategies of these evolutions (Source: Stan L-M., 2011, p. 22, revised)

Nevertheless, as the system gets bigger and more complex the exploitation of the entire SYNP becomes more difficult, because of several factors: (a) the system's internal bureaucracy which is higher, $(b)$ the reward systems which concern more the individual or team performances, generating unfair competition and poor communication between units, $(c)$ the increasing of the risk of capacities/resources' wrong positioning among collaborative networks, $(d)$ the increasing numbers of interest groups with different expectations and requirements. Consequently, it will occur a more evident emergence of the synergistic opportunities which are not (optimally) exploited, of the efforts and capacities that are not (enough) combined and of increasing expenses for resources' requirements which could have been assured through synergy. Therefore, SYNP is exploited even more as: (1) its value is better identified/awarded within and outside the network; (2) the competitive conditions require the proliferation of added values generable through synergy; (3) the undertaken synergistic strategies aim also at the combined increased effect at the entire level. When the entities start to be affected because of their age (because of the processes' rigidity, the excessive bureaucracy and other elements related to an im- 
proper motivation of the collaborative intercessions), their SYNP size is reduced. But these disequilibriums often induce a comprehensive thinking of the value chains (when most of the mergers and alliances do take place), facilitating reorganizations, the creation of new collaborative relationships and a wider exploitation of the available SYNP thorugh a globally rethought synergistic infrastructure.

\section{The Role of Information in Supporting the Synergistic Infra- structure and Adequate Exploitation of Synergistic Potential}

The synergistic infrastructure of the open economic system (and not only economic) represents the assembly of tangible and intangible elements which correlated functions sustain the contouring of synergy effects necessary to the system; these elements belong also to other collaborative entities, the synergistic system/network continuously interacting with their environment. Hereby, true synapses (contact points) are built between strategies and internal and external capacities. The key elements which identify the synergistic infrastructure of any economic network or system - in the context of pursuing of a higher level of their competitiveness -, are necessarily the following, too: technology (including innovation, information and ICT) and education (especially the accessibility of knowledge and abilities, and their positioning in the maximum efficiency workstations) - elements that conditionate increases in the tangible and intangible values of a long series of interdependences. The synergism requires to directly know-what (the actions) towards know-who (networking with the most adequate partners) through know-how (practical knowledge to do these things), at the basis of all these standings being know-why (the sciences which sustain the collaborative activities of production entities):

\begin{tabular}{|l|l|}
\hline $\begin{array}{l}\text { "KNOW-WHO" } \\
\text { (NETWORKING) }\end{array}$ \\
\begin{tabular}{|l|l|}
\hline "KNOW-WHAT" \\
(ACTIONS, ACTIVITIES)
\end{tabular} & \\
\hline $\begin{array}{l}\text { "KNOW-HOW" } \\
\text { (KNOWLOWGE) }\end{array}$ & \\
\hline $\begin{array}{l}\text { KNOW-WHY" } \\
\text { (SCIENCES) }\end{array}$ & \\
\hline
\end{tabular}

Fig. 4. The open economic system's synergistic infrastructure - product of an evolved economic situation. This infrastructure applicable or valid for other types of systems, too.

The adequate identification of the synergistic infrastructure also helps us to better appreciate the real possibilities of SYNP exploitation and especially the role played by the collaborative flows in the actual exploitation of this potential. „In order to quantify the degree of the usage of the synergistic relational potential of the economic network or of an open economic system, the accounting of mutual information flows is essential, these ones being basic elements that facilitate the shaping of multiple and valuable synergies within the economic entity" [28]. Besides the number of activated network links (having/transporing mutual information flows), the formula of actually exploited SYNP also comprises their intensity (the number of links created in time) and quality (the quality of information and other qualitative aspects intended by the network coordinators) so as the shared information to correspond to the entity's needs and to guarantee the superiority in value of the network links. The satisfaction degree 
of information needs is expressed as a percentage because we deal with real (and not with ideal) economic networks and it may be known for a unique moment, $t$ [28]:

$$
S Y N P^{t}=\sum \frac{L_{A}^{t}}{L^{t}} \cdot q s^{2}
$$

If we take into account the current existent and not-yet-existent (but latent) links which are necessary and should be established (and also activated), it will result the total SYNP at moment $t$ :

Where:

$$
S Y N P_{T}^{t}=\Sigma q s^{t}
$$

$S Y N P_{A}=$ the actual synergistic potential effectively exploited, used, which can be taken into account $S Y N P_{T}=$ the total, theoretical, nominal (of reference) synergistic potential, valid for the synergistic potential of the economic network in moment $t$

$L_{A}^{t}=$ the number of activated network links (that have/sustain mutual information flows) in moment $t$ $L^{t}=$ the number of network links in moment $t$

$q=$ quality parameter (parameter concerning the quality of information and other qualitative aspects intended by the network coordinators)

$s^{t}=$ the satisfaction ratio of information needs (in the moment $t$ ) of the total information needs belonging to the network links.

Besides the capacity of knowing and comparing the SYNP exploited by different entities, this formula helps us understand that: $(i)$ synergies suppose the procurement of some significant added values in contexts where information is complementary used, in an integrated, transparent and coordinated manner, the dispersed information/knowledge's totality and utility being superior to the quantitative amount of the dispersals achievable through separate efforts [29]; (ii) the information flows between the component sybsystems of an economic entity represent integrated parts of the SYNP exploitation and in connection with which we can study the roles of network flows, information entropy, turning points in collaboration etc.

\section{Conclusions}

Synergy represents a complex, but real experience. It means the condition and also the sign of living networks' vigor and dynamics, reflecting a series of undertakings and collaborative nurtured options in order to obtain a less conventional competitive advantage in the economic environment (and not only economic).

The current presentation has evidenced the necessity of an integrative manner of open economic system's synergy's approaching in the contemporary economy. As the economic entities pass towards the stage of natural (of more profound networking with the elements of the environment in which they operate), they implicitly become more interested in the synergy topic.

Synergetic Economics, framed in six distinctive phases of approaching, studies the specific phenomena of the economic systems in transformation, with a view to acquire dynamic equilibrium. It does not deal only with different activities that combine in order to achieve a common exponentially goal, but it also constitutes a science of self-(re)organization of open economic systems, on the basis of their constituent units' comprehensive collaborative relations, generating globally special behaviors. 
The transitioning phaze from the order to the disorder state (or from the state of equilibrum to the disequilibrum one) constitutes a critical point at which the systems or networks are becoming synergistic, "the apparent chaos" having a profound role in enhancing the advantageous/superior reorganization of the system's/network's elements through innovated or rethought collaborative processes.

Economic, informational, social and cultural elements may be congregated in a set of determinants of the synergistic actions in economy: the case of the synergistic gravity equation ( $S Y N G E q$ ) which helps us compare the synergistic determinants of different systems/networks which are in competition.

The systems' synergistic potential (SYNP) amplifies as the complexity of these entities or of included networks grows; percentagly speaking, the SYNP exploitation's degree varies depending on the systems' organizational structure and their developing stage, being maximum in the first evolutionary period and minimum in the relative stability stage of these entities.

The economic system's synergistic infrastructure includes support elements for creating added value (sciences and knowledge) and elements that actively upkeep the synergistic intercessions in economy (actions and networking); such an infrastructure represents a part and parcel of the environment's competitive conditions in which that entity operates, directly influencing the intensity of synergistic efforts and the value of resulted synergistic effects.

The information flows (the quality and intensity of dispersed information, besides the number of activated network links and the satisfaction ratio of the network's or system's information needs) are essential to SYNP exploitation.

The synergistic network, as part of the open economic system, is an active network, oriented towards the internal possibilities and the requirements of the external environment in which it operates. Therefore, the Synergetic Economics is assisted by varied interdisciplinary perspectives, finding and emphasizeing connections/links between seemingly disparate elements (technology, culture, ecology, social groups etc.), which influence the intensification of this remarkable nonlinear phenomenon - synergy - with so many important effects in economy.

\section{References}

1. Sirower, M. L., The Synergy Trap: How Companies Lose the Acquisition Game, The Free Press, Avenue of Americas, New York, 13 (2000)

2. Stan, L-M., The Necessity to Exploit the Economic Network's Synergistic Potential, LAP LAMBERT Academic Publishing, Saarbrücken, Germany, 5. 33. 37-38 (2011)

3. Merriam Webster Dictionary: http://www.merriamwebster.com $/$ medical $/$ synergize?show $=0 \& \mathrm{t}=1289571154$

4. Buckminster Fuller, R., No more secondhand God: and other writings, Southern Illinois University Press, 123-161 (1963)

5. Ansoff, I.H., Corporate Strategy: An Analytic Approach to Business Policy for Growth and Expansion, McGraw-Hill, 167 (1965)

6. Ansoff, I.H., From Strategic Planning to Strategic Management, Wiley, 102-147 (1976) 
7. Ansoff, I.H., McDonnell E.J., The New Corporate Strategy, Wiley, $62-97$ (1988)

8. Buckminster Fuller, R., Nine Chains to the Moon, Anchor Books, 252 (1971)

9. Bode, H.W., "Synergy: Technical Integration and Technological Innovation in the Bell System”, Bell Laboratories, 9-26 (1971)

10. Coulter, N.A. Jr., Synergetics: an adventure in human development, Wichita Human Study Group, Prentice-Hall, 15 (1976)

11. Porter, M., Avantajul concurențial. Manual de supraviețuire şi creștere a firmelor în condițiile economiei de piaţă, Editura Teora, Bucureşti, 300-301 (2001)

12. Rappaport, J., Swift, C., Hess R. (eds.), Studies in Empowerment: Steps Toward Understanding and Action, Routledge, 201-207 (January, 1984)

13. ***, Le Robert MICRO. Dictionnaire de la langue française, Edition Poche, Pierrede-Coubertin, Paris, 1290 (2006)

14. ***, Macmillan English Dictionary for Advanced Learners, Bloomsbury Publishing Plc, 1457 (2006)

15. Faulkner, D., Bowman, C., Elemente de strategie concurenţială, Editura Teora, Bucureşti, 7-8. 92 (2000)

16. Harris, P. R., The New Work Culture: HRD Transformational Management Strategies, HRD Press, Amherst, U.S.A., 58 (1998)

17. Dundon, E., The Seeds of Innovation. Cultivating the Synergy that Fosters New Ideas, AMACOM, Broadway, New York, 13 (2002)

18. Dreikorn, M. J., The Synergy of One. Creating High-Performing Sustainable Organizations through Integrated Performance Leadership, ASQ Quality Press, Milwaukee, Wisconsin, U.S.A., 15-21 (2004)

19. Maxwell, J. C., Winning with People. Discover the People Principles that Work for You Every Time, Thomas Nelson, Inc., Nashville, Tennessee, 228-231 (2004)

20. Buckingham, M., Coffman C., Manager contra curentului. Ce fac marii manageri altfel decât ceilalţi, Editura ALFA, Bucureşti, p. 32-35 (2007)

21. Portugali, J., Self-organization and the City, Springer-Verlag, Berlin, 330 (2000)

22. Aaker, D.A., McLoughil, D., Strategic Market Management. Global Perspectives, John Wiley \& Sons, Ltd., West Sussex, United Kingdom, 140-141 (2010)

23. Corning, P.A., „Synergy Goes to War: A Bioeconomic Theory of Collective Violence", Journal of Bioeconomics, Springer, 9:2 (2007)

24. Ivancevic, V. G., Ivancevic, T. T., Complex Nonlinearity: Chaos, Phase Transition, Topology Change, and Path Integrals, Springer, 649 (2008)

25. Meijers, E., Synergy in Polycentric Urban Regions. Complementarity, organising capacity an critical mass, Haveka, Alblasserdam, Netherlands, 14-25 (2007)

26. Lybeck, J.A., Istoria globală a crizei financiare (2007-2010), Editura Polirom, Bucureşti, 45. 266 (2012)

27. Fung, K.V., Fung, K.W., Wond, Y., Concurenţa într-o lume plată. Cum să construim o companie într-o lume fără graniţe, Editura Publica, Bucureşti, 121 (2009)

28. Stan, L.M., Jivan A., "The Exploitation of the Open Economic System's Synergistic Relational Potential", JKMEIT Scientific Papers, Volume II, Issue 2, France, 13.1516 (April 2012)

29. Jivan, A., Servicitate. Mai mult decât productivitate în economia de serviciu, Editura SEDONA, Timişoara, 115 (2000) 